\title{
The Role of Eumelanin in Generating Reactive Oxygen and Reactive Nitrogen in Solution: Possible Relevance to Keloid Formation
}

\author{
Julian M. Menter ${ }^{1}$, Comnuan Nokkaew ${ }^{2}$, Danita Eatman ${ }^{3}$, Aquilla Sprewell $^{1}$, Natalia Silvestrov ${ }^{3}$, \\ Abrienne M. Patta ${ }^{1}$, Sandra Harris-Hooker ${ }^{2}$ \\ ${ }^{1}$ Department of Microbiology, Biochemistry and Immunology, Morehouse School of Medicine, Atlanta, USA \\ ${ }^{2}$ Office of Sponsored Research, Department of Pathology, Morehouse School of Medicine, Atlanta, USA \\ ${ }^{3}$ Analytical Laboratory, Department of Pharmacology and Toxicology, Morehouse School of Medicine, Atlanta, USA \\ Email: jmenter@msm.edu
}

Received March 26, 2013; revised April 25, 2013; accepted May 1, 2013

Copyright (C) 2013 Julian M. Menter et al. This is an open access article distributed under the Creative Commons Attribution License, which permits unrestricted use, distribution, and reproduction in any medium, provided the original work is properly cited.

\begin{abstract}
Recently, nitric oxide (NO) has been implicated as an epigenetic factor in keloids, a scarring disease occurring primarily in dark skinned people who have relatively high amounts of pigment melanin. In this work, we tested whether a melanin-mediated redox reaction involving adsorbed $\mathrm{NO}$ and $\mathrm{O}_{2}$ can couple $\mathrm{NO}$ oxidation with $\mathrm{O}_{2}$ reduction to form reactive oxygen species (ROS) or reactive nitrogen species (RNS) in vitro at $\mathrm{pH}$ 7.4. We measured the formation of reactive species that oxidize dihydrorhodamine123 (DHR) to fluorescent rhodamine123 in the presence and absence of sepia melanin. In separate experiments, we monitored NO concentration with 4,5-diaminofluorescein (DAF) by measuring the highly fluorescent NO-adduct, DAF-2T. We attempted to detect peroxynitrite with $5 \mu \mathrm{M} 3$-methyl-1,2-cyclopentanedione (MCP), a selective scavenger of peroxynitrite (IC50 $=3.6 \mu \mathrm{M}$ for $\mathrm{ONOO}^{-}$vs. $63.8 \mu \mathrm{M}$ and $>>100 \mu \mathrm{M}$ for $\mathrm{NO}$ and $\mathrm{O}_{2}^{-}$respectively). However, MCP itself oxidized DHR. We found that in the absence of NO, melanin itself oxidizes DHR, with no loss of DAF-fluorescence (i.e. no net consumption of NO). In the presence of NO, there was a $\sim 57 \%$ loss of DAF fluorescence, indicating that $\mathrm{NO}_{\mathrm{x}}$ is formed at the expense of NO. The data provided good fit $\left(r^{2}=\right.$ $0.94)$ to a Langmuir adsorption isotherm, with pseudo first order rate $\left.k^{\prime}=8.2 \times 10^{7}\right) \mathrm{s}^{-1}$ and adsorption coefficient $K_{a d}=$ $4.04 \mathrm{M}^{-1}$. Both of these parameters are consistent with a facile chemisorption reaction between $\mathrm{NO}$ and $\mathrm{O}_{2}$ on the melanin surface. Possible reactions are a) $\mathrm{NO}$ and $\mathrm{O}_{2}^{-} \rightarrow \mathrm{ONOO}^{-}$and/or b) $2 \mathrm{NO}+\mathrm{O}_{2} \rightarrow 2 \mathrm{NO}_{2}$. The latter reaction is disfavored in solution but is significantly accelerated on the melanin surface via an entropy effect.
\end{abstract}

Keywords: Melanin; Nitric Oxide; $\mathrm{NO}_{\mathrm{x}}$; Redox

\section{Introduction}

Pigment eumelanin binds a wide variety of compounds [1] and can act as a redox reagent [2,3]. Depending on its chemical environment, melanin can either donate or accept electrons from ambient molecules and/or couple the oxidation of one compound with the reduction of another [4-6]. Melanin is well known to undergo autoxidation as well as Fenton chemistry with bound or adventitious transition metals (usually iron or copper) to produce $\mathrm{OH}$ radicals. Depending on the relative metal and pigment concentrations, melanin may act as either an antioxidant or a pro-oxidant $[7,8]$.
People of color are particularly susceptible to keloids, a recalcitrant consequence of aberrant wound healing, characterized by excessive collagen deposition that extends beyond the original wound [9-11]. The etiology of keloids is complex, and both genetic [12] and epigenetic [13] factors are involved. Recent work [14-16] has indicated that nitric oxide (NO) enhances the synthesis of type I collagen by dermal fibroblasts and that the keloid lesion may arise from the NO/cGMP signaling pathway. The particular susceptibility of darkly-pigmented persons to keloids is intriguing, and it leads one to ask whether pigment itself may play an active role in keloid pathogenesis, given its ability to bind and mediate redox 
reactions of bioactive molecules.

Recently, [4] we demonstrated that sepia melanin scavenged NO in solution through a cellulose dialysis membrane. Crippa et al. [17] demonstrated that molecular $\mathrm{O}_{2}$ was adsorbed by melanin, and our observation of NO scavenging by melanin suggested a similar adsorption process for NO. We thought it quite conceivable that the scavenged nitric oxide could be oxidized to additional reactive nitrogen species (RNS; $\mathrm{NO}_{\mathrm{x}}$ ) by direct redox reaction with melanin and/or with adsorbed $\mathrm{O}_{2}$ or reactive oxygen species (ROS) that arose in the course of melanin autoxidation $[2,3]$. We used dihydrorhodamine 123 (DHR) oxidation to measure the formation of ROS and RNS in vitro at $\mathrm{pH} 7.4$ in the presence and absence of added NO. We show that melanin can adsorb $\mathrm{NO}$ and couple the oxidation of $\mathrm{NO}$ with the reduction of $\mathrm{O}_{2}$.

\section{Methods}

Buffer: All experiments were carried out in $0.1 \mathrm{M}$ phosphate buffer ("buffer") pH 7.4 made up in ultrapure deionized water. In several experiments, buffer was passed through a Chelex-100 resin column $(8.0 \times 1.0 \mathrm{~cm})$ before use. This treatment had no effect on the results.

Melanin preparation: Impure sepia melanin was obtained as a kind gift from Dr. Miles Chedekel (MelanInk@). Protein was removed by incubating this sample at $60^{\circ} \mathrm{C}$ for $30 \mathrm{~min}$ in $0.1 \mathrm{M} \mathrm{HCl}$ followed by predialysis through a Spectropore membrane (MW cutoff $6-8 \mathrm{kD}$ ) into $100 \mathrm{~mL} 0.1 M$ phosphate buffer, $\mathrm{pH}$ 7.4/0.1 M EDTA, followed by two changes of $0.1 \mathrm{M}$ buffer alone.

Nitric oxide-generating compounds: We used freshly-prepared stock solutions of $0.1 \mathrm{mg} / \mathrm{ml}$ S-nitorso-Nacetyl-DL-penicillamine (SNAP; Sigma Chemical Co.) dissolved in $2.0 \mathrm{ml} \mathrm{95 \%}$ ethanol and diluted to $10 \mathrm{ml}$ with buffer (final concentration $4.5 \times 10^{-5} \mathrm{M}$ ). Donors ( $250 \mu \mathrm{l}$ of $0.02 \mathrm{mg} / \mathrm{ml}$ diluted stock) were added to test and control dialyzates in a total of $22 \mathrm{ml}$ in a $25-\mathrm{ml}$ graduated cylinder under mechanical stirring. All reactions involving use of SNAP were carried out in subdued light.

Detection of nitric oxide: Nitric oxide reacts with 4,5diaminofluorescein (DAF) in the presence of molecular $\mathrm{O}_{2}$ to form a highly fluorescent triazole (DAF-2T) [18]. Fluorometric measurements were made on $200 \mu \mathrm{l}$ aliquots of control and test dialyzates, which were diluted to $1.0 \mathrm{ml}$ in separate plastic cuvettes. At time $t=0,1.0$ $\mathrm{ml}$ of SNAP solution was added to each cuvette and the DAF-2T fluorescence intensity (excitation $495 \mathrm{~nm}$, emission $515 \mathrm{~nm}$ ) measured in a Perkin-Elmer 650 - 40 Fluorescence Spectrophotometer (Perkin Instruments, Norwalk, CT) as a function of time. The dialyzates of the control and test samples $(200 \mu \mathrm{l})$ were analyzed for NO at times ranging from 0 to 120 minutes. Steady-state fluorescence levels were reached at 60 minutes under our experimental conditions. Data were expressed as the ratio sample/control (SNAP alone) at $\mathrm{t}=100$ minutes.

The Interaction of Sepia Melanin with nitric oxide: The reaction system consisted of $22 \mathrm{ml} 0.1 \mathrm{M}$ phosphate buffer $(\mathrm{pH}=7.4)$ in a $25 \mathrm{ml}$ graduated cylinder, surrounding dialysis bags that contained either a $5 \mathrm{ml}$ suspension of $5 \mathrm{mg}$ sepia melanin or $5 \mathrm{ml}$ buffer alone (see below). Nitric oxide levels were measured from the test and control dialysis filtrates as previously described [4].

Detection of $\mathrm{NO}_{\mathrm{x}}$ : Oxidation of dihydrorhodamine 123 (DHR): Dialysis systems were prepared as before, with the addition of $1.0 \mathrm{ml}$ of $2.0 \mathrm{mM}$ dihydrorhodamine 123 (DHR; Life Sciences) in $25 \mathrm{ml}$ of total solution. Control systems were a) SNAP (NO) alone (blank); b) SNAP (NO) + DHR (NO control); c) Melanin + DHR (melanin control). Test systems contained d) Melanin + DHR + SNAP (NO). (Oxidized) rhodamine fluorescence (excitation $475 \mathrm{~nm}$; emission 540) was recorded for 0.5 $\mathrm{ml}$ aliquots of test and control systems as functions of time.

Estimation of the rate of NO oxidation: After correcting the DHR oxidation curves for melanin-produced $\mathrm{OH}$, which oxidizes DHR $[2,3,19]$, we used the initial part of the DHR oxidation curves which yielded reasonably straight lines and avoided build-up of secondary RNS products (e.g. $\mathrm{NO}_{2}$ ) that could oxidize DHR [19]. Under these conditions, the rate of DHR oxidation is taken to be equal to the rate of disappearance of NO. For data analysis, the net oxidation of DHR by $\mathrm{NO}_{\mathrm{x}}$ was determined by subtracting the contribution of each control curve (see Figure 1, below). The corrected rate of DHR oxidation by $\mathrm{NO}$ is proportional to the melanin-mediated formation of $\mathrm{NO}_{\mathrm{x}}$. The steady state concentration of $\mathrm{NO}$ $(t)$ is proportional to added SNAP concentration at $t=0$. We found the relationship between Rhodamine fluorescence and $\mathrm{NO}_{\mathrm{x}}$ concentration by means of a standard curve.

*For further discussion, see Appendix.

Langmuir adsorption isotherm of melanin-coupled redox reaction(s) $[4,20]$ : The Langmuir adsorption isotherm assumes that the reaction takes place with the reactants chemisorbed to the melanin surface. If $\theta_{\mathrm{NO}}$ and $\theta_{\mathrm{O}_{2}}$ are the fractions of $\mathrm{NO}$ and $\mathrm{O}_{2}$ melanin binding sites bound by $\mathrm{NO}$ and $\mathrm{O}_{2}$ respectively, we have:

$$
V=k \theta_{\mathrm{NO}} \theta_{\mathrm{O}_{2}}=k^{\prime} \theta_{\mathrm{NO}}
$$

The Langmuir treatment yields [20]

$$
\theta_{\mathrm{NO}}=K_{a d}[\mathrm{NO}] / 1+K_{a d}[\mathrm{NO}]
$$

where [NO] is the solution concentration of NO in $M, K_{a d}$ $=k_{a} / k_{d}$ is the adsorption coefficient, i.e. the ratio of ad- 


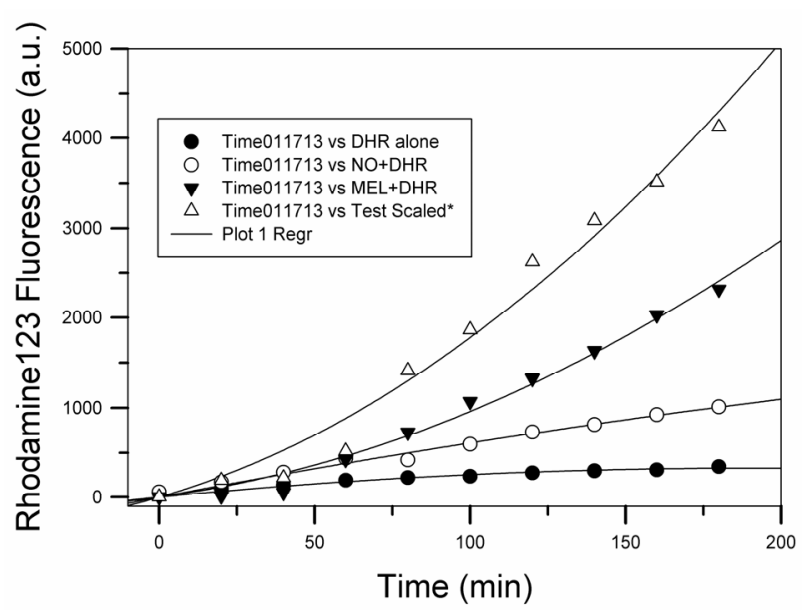

Figure 1. Oxidation of DHR by NO (white circles), Eumelanin (black triangles) and Eumelanin/NO system (white triangles) in $0.1 M$ phosphate buffer, pH 7.4 (see text). DHR is slowly autoxidized (black circles). In the absence of added melanin, NO slowly oxidizes DHR (white circles). Melanin itself oxidizes DHR at a significantly greater rate with significant upward concavity (black triangles); the additional increases in DHR oxidation and concavity in the presence of NO suggests the generation of $\mathrm{NO}_{\mathrm{x}}$ (white triangles).

sorption/dissociation constants of $\mathrm{NO}$ on the melanin backbone, having the units of $\mathrm{M}^{-1}$. We assume that $k^{\prime}=k \theta_{\mathrm{O}_{2}}$ in $\mathrm{O}_{2}$ saturated (aerated) solution, is equal to the pseudo first order rate constant for the bimolecular reaction between $\mathrm{O}_{2}$ and $\mathrm{NO}$ on the melanin surface having the dimensions of $\mathrm{s}^{-1}$ (see $[17,20]$ for discussion).

Substitution of (2) into (1) followed by inversion yields

$$
1 / V=1 / k^{\prime} K_{a d}[\mathrm{NO}]+1 / k^{\prime}
$$

Thus, if Langmuir mechanisms are operative, slopes of $1 / V$ vs. $1 /[\mathrm{NO}]$ will yield a straight line with slope $1 / k^{\prime} K_{a d}$ and intercept $1 / k^{\prime}$ from which parameters $k^{\prime}$ and $K_{a d}$ can be found.

The steady state concentration, $[\mathrm{NO}]_{\mathrm{ss}}$ was estimated from rate constants for formation and decline of $\mathrm{NO}$ in consecutive reactions. These constants were found from the approximate lifetimes of SNAP ( $\sim 5 \mathrm{hr}$,) and NO decomposition in aqueous solution ( $\sim 2 \mathrm{~s})$. Under these conditions, NO is consumed virtually as fast as it is formed, and [NO] could be assumed to be invariant with time. Using these values, the integrated rate equation [20] ultimately yielded the value:

$$
[\mathrm{NO}]_{\mathrm{ss}}=1.12 \times 10^{-4}\left[\operatorname{SNAP}_{(0)}\right]^{*} .
$$

*For further discussion, see Appendix.

Statistical analysis: We used Student's $t$ test for small samples. Data were expressed as mean $\pm \boldsymbol{S D}$. Differences were considered significant for $\mathrm{p}<0.05$.

\section{Results}

DHR oxidation: Figure 1 shows the results of a representative experiment $(\mathrm{n}=4)$ in aerated solution. Control groups were DHR alone (black dots); $D H R+N O$ in the absence of melanin (white dots) and melanin $+D H R$ (black triangles). DHR alone was slowly autoxidized to fluorescent rhodamine 123 . Nitric oxide modestly increased the rate of DHR oxidation Melanin efficiently oxidized DHR with significant upward concavity. The test system, melanin + NO + DHR (white triangles), further increased the rate of growth and concavity. Qualitatively similar results were obtained for each experiment.

Attempts to Detect $\mathrm{NO}_{\mathrm{x}}$; Consumption of $\mathrm{NO}$ in solution: At $5 \mu \mathrm{M}$, 3-methyl-1,2-cyclopentanedione (MCP; Aldrich Chemical Co.) selectively scavenges $\mathrm{ONOO}^{-}$ $\left(\mathrm{IC} 50=3.6 \mu \mathrm{M}\right.$ for $\mathrm{ONOO}^{-}$vs. $63.8 \mu \mathrm{M}$ and $>>100 \mu \mathrm{M}$ for $\mathrm{NO}$ and $\mathrm{O}_{2}^{-}$respectively [21]. Although we originally planned to use MCP to detect peroxynitrite, this did not prove successful, since MCP itself oxidized DHR, (not shown). However, we did test for NO consumption in the test system and control samples by using 4,5-diaminofluorescein (DAF-2; Sigma Chemical Co.) which forms a highly-fluorescent triazole adduct with NO, (DAF2T), [18] and which does not react with DHR. Figure 2 shows that $5 \mu \mathrm{M}$ MCP scavenges $\mathrm{NO}$ at $\sim 20 \%$ (Figure 2(b)). Nitric oxide consumption by melanin alone in the course of DHR oxidation does not occur (compare Figures 2(b) with 2(c)). However, the simultaneous presence of melanin and NO (Figure 2(d)) resulted in consumption of NO by an additional $57 \%$, suggesting concomitant $\mathrm{NO}_{\mathrm{x}}$ formation at the expense of $\mathrm{NO}$.

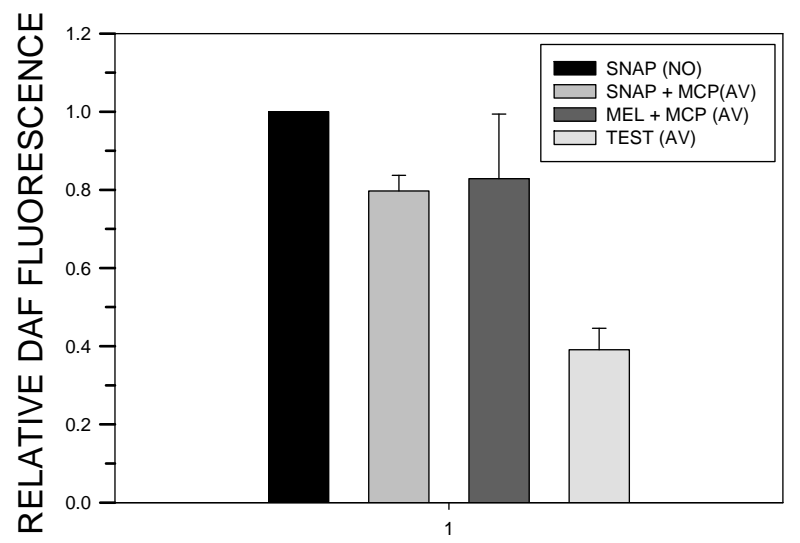
(a)
(b)
(c)
(d)

Figure 2. Disappearance of NO (SNAP) in the presence of sepia melanin in oxygen-saturated solution. DAF forms a highly fluorescent triazole DAF-2T in presence of NO. MCP $(5 \mu \mathrm{M})$ scavenges virtually all ONOO (IC 50 = 3.6 $\mu \mathrm{M}$ ), but only slightly scavenges NO (IC $50=63.3 \mu \mathrm{M})$, Taken together, Figures 1 and 2 suggest $\mathrm{NO}_{\mathrm{x}}$ is formed at the expense of NO. (a) SNAP (NO) alone; (b) SNAP + MCP; (c) Melanin + MCP; (d) Melanin + MCP + SNAP. Data are expressed as mean $\pm S . D, n=4$. 
Kinetic Analysis of Melanin-Mediated NO $_{x}$ Formation: Previously, we and others have found that melanin can couple oxidation of one species with reduction of another. To test the hypothesis that melanin can mediate a redox reaction involving $\mathrm{NO}$ [4] and $\mathrm{O}_{2}$ [17] adsorbed on its surface, we analyzed our data according to a simple Langmuir adsorption isotherm [20].

Figure 3 shows a Langmuir plot of $1 / V$ vs. 1/[NO]. This plot yielded a straight line, in good agreement with the Langmuir model $\left(r^{2}=0.94\right)$. From the slope and intercept, we obtained a value of pseudo first order constant $k^{\prime}=8.2 \times 10^{7} \mathrm{~s}^{-1}$ and adsorption coefficient $K_{a d}=$ $4.04 \mathrm{M}^{-1}$.

\section{Discussion}

In the absence of sepia melanin, NO in aerated solution slowly oxidizes indicator DHR. Sepia melanin alone oxidizes DHR rapidly, but the addition of NO still further increases the rate of DHR oxidation. Figure 1 indicates that there is a synergistic effect in DHR oxidation when both melanin and NO are present.

Sepia melanin is known to consume $\mathrm{O}_{2}$ in aerated solution, producing $\mathrm{H}_{2} \mathrm{O}_{2}$ via a superoxide intermediate $[2,3]$. Neither superoxide $\mathrm{H}_{2} \mathrm{O}_{2}$ nor physiological $\mathrm{NO}$ concentrations will oxidize DHR, however, $\mathrm{OH}$ does oxidize DHR to fluorescent Rhodamine123 [19]. Hydroxyl

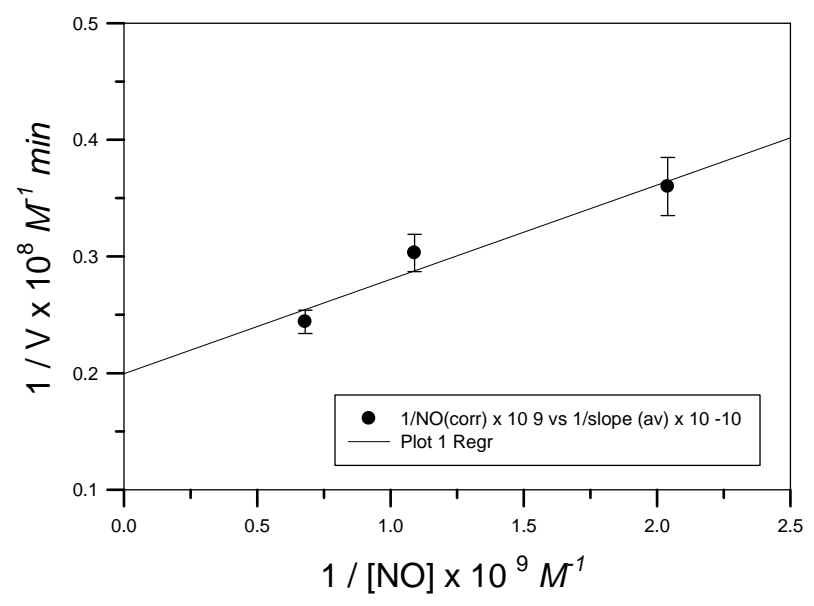

Figure 3. Langmuir Adsorption curve for $\mathrm{NO}+\mathrm{O}_{2}$ coupled redox reaction on sepia melanin surface. After correction for production of ROS by melanin, oxidation of DHR by NO in solution and spontaneous oxidation of DHR by ambient $\mathrm{O}_{2}$ (see Figure 1), rates of production of $\mathrm{NO}_{\mathrm{x}}$ were measured by rhodamine 123 fluorescence measurements (see methods section). Steady-state [NO] as a function of time was estimated from SNAP decomposition rates and from the lifetime of NO in aqueous solution (see text). Plots of $1 / V$ vs. $1 /[\mathrm{NO}]$ afforded a straight line, $\left(r^{2}=0.94\right)$ that intersected the $1 / \mathrm{V}$ axis above the origin, strongly indicating a chemisorption mechanism, with adsorption coefficient $K_{a d}$ $=4.04 \mathrm{M}^{-1}$ and $k^{\prime}=4.98 \times 10^{9} \mathrm{~min}^{-1}=8.2 \times 10^{7} \mathrm{~s}^{-1}$. radical could be generated from decomposition $\mathrm{ONOOH}$ at pH 7.4, [20] natural sepia melanin, [3] as well as adventitious and/or melanin-bound iron and copper ions. Bound transition metals are very difficult to remove, even after exhaustive dialysis against EDTA [1].

Figure 2 shows that under these experimental conditions, the $\mathrm{NO}_{\mathrm{x}}$ scavenger MCP does not scavenge ROS (compare Figures 2(b) and (c)). However, MCP will oxidize DHR (not shown). As indicated in Figure 2, 5.0 $\mu \mathrm{M}$ MCP scavenges $\sim 20 \%$ of NO. There is an additional $57 \%$ NO consumption in the presence of added NO, presumably via formation of $\mathrm{NO}_{\mathrm{x}}$. The results from Figure 2 confirm that the DHR-oxidizing species from melanin in the absence of $\mathrm{NO}$ is not $\mathrm{NO}_{\mathrm{x}}$.

Crippa et al. [17] demonstrated that molecular $\mathrm{O}_{2}$ is adsorbed by melanin. We have observed melanin scavenging of NO that suggests a similar adsorption process [4]. The observed fit of our data to a simple Langmuir adsorption isotherm strongly suggests that the melaninmediated reactions leading to increased DHR oxidation do involve adsorbed $\mathrm{NO}$ and $\mathrm{O}_{2}$ species. It seems reasonable that sepia melanin could couple NO oxidation with oxygen reduction to $\mathrm{O}_{2}^{-}$. Superoxide and $\mathrm{NO}$ might then combine to form $\mathrm{ONOO}^{-}$in a fast reaction $\left(k_{\mathrm{NO}+\mathrm{O}_{2}}=1.6 \times 10^{10} \mathrm{M}^{-1} \cdot \mathrm{s}^{-1}\right) \quad$ [22]. Alternatively, 2 adsorbed NO molecules in close proximity to molecular $\mathrm{O}_{2}$ could react to form $\mathrm{NO}_{2}$ and other $\mathrm{NO}_{\mathrm{x}}$ species. In the absence of melanin the reaction of 2 molecules of $\mathrm{NO}$ with one molecule of $\mathrm{O}_{2}$ to afford 2 molecules of $\mathrm{NO}_{2}$ is slow, (pseudo second order constant,

$\left.k_{\mathrm{NO}+\mathrm{O}_{2}}=4 \times 10^{4} \mathrm{M}^{-1} \cdot \mathrm{s}^{-1}\right)$ at $\mathrm{NO}$ saturation, $(\sim 2 \mathrm{mM}$ in aqueous solution), because it depends on a simultaneous attack of two molecules of $\mathrm{NO}$ on a molecule of $\mathrm{O}_{2}$ [23]. However, in adsorbing ("ordering") $\mathrm{NO}$ and $\mathrm{O}_{2}$ on its surface, melanin might well facilitate formation of $\mathrm{NO}_{2}$, by significantly decreasing the entropy of the reaction. Our data does not presently allow distinction between these mechanisms.

Although comparison of our rate constant with solution data is not straight-forward because of complications having to do with the melanin surface, our value of $8.2 \times$ $10^{7} \mathrm{~s}^{-1}$ is in reasonable agreement with a value obtained from Crippa [17] who used a more rigorous treatment to obtain a value of $5.7 \times 10^{6} \mathrm{~s}^{-1}$ for reduction of dioxygen by conduction band electrons of colloidal melanin (for discussion, See [17]).

Hsu et al. [16] found that keloid tissue expression showed significant increases in iNOS gene, $\mathrm{NO}_{\mathrm{x}}$ production, type I collagen mRNA, and type I collagen protein expression compared to normal fibroblasts. Our present work demonstrates that melanin adsorbs NO and mediates oxidation to $\mathrm{NO}_{\mathrm{x}}$, with possible epigenetic cones- 
quences. Although the consequences of these interactions are not well known with respect to keloids, one might gain insight by considering the closely-related case of systemic sclerosis, where imbalances in NO metabolism, type I collagen expression, and the occurrence of nitrated proteins have been known to occur for certain disease states [24-26]. Melanin sequestration of NO and its role in generating toxic $\mathrm{NO}_{\mathrm{x}}$ might have similar effects on normal fibroblasts that could possibly result in their transformation to keloid fibroblasts. This latter question is currently under investigation in our laboratory (Nokkaew et al., in progress).

\section{Conclusions}

a) Sepia melanin accelerates (couples) the oxidation of $\mathrm{NO}$ to $\mathrm{NO}_{\mathrm{x}}$ and the reduction of molecular $\mathrm{O}_{2}$ in buffered aqueous solution.

b) The reaction kinetics fit well to a simple Langmuir adsorption isotherm, and the reaction therefore appears to take place between adsorbed $\mathrm{NO}$ and $\mathrm{O}_{2}$ via a chemisorption mechanism. We obtained a value of pseudo first order constant $k^{\prime}=8.2 \times 10^{7} \mathrm{~s}^{-1}$ and adsorption coefficient $K_{a d}=4.04 \mathrm{M}^{-1}$.

c) Such a reaction occurring in situ in dermal tissue might have significant epigenetic consequences in keloid formation or related pathologies.

\section{Acknowledgements}

This work was funded in part by GRANTS: MBRS \#GM08248, RCMI \#8G12MD007602, and DOD \# 911 NF-10-1 0448. There are no conflicts of interest.

\section{REFERENCES}

[1] L. Hong and J. D. Simon, "Current Understanding of the Binding Sites, Capacity, Affinity, and Biological Significance of Metals in Melanin" The Journal of Physical Chemistry B, Vol. 111, No. 8, 2008, pp. 7938-7947. http://dx.doi.org/10.1021/jp071439h

[2] W. Korytowski, P. Hintz, R. C. Sealy and B. Kalyanaraman, "Mechanism of Dismutation of Superoxide Produced during Autoxidation of Melanin Pigments," Biochemical and Biophysical Research Communications, Vol. 131, No. 2, 1985, pp. 659-665. http://dx.doi.org/10.1016/0006-291X(85)91288-4

[3] W. Korytowski, B. Pilas, T. Sarna and B. Kalyanaraman, "Photoinduced Generation of Hydrogen Peroxide and Hydroxyl Radicals in Melanins," Photochemistry and Photobiology, Vol. 45, No. 2, 1987, pp. 185-190. http://dx.doi.org/10.1111/j.1751-1097.1987.tb05362.x

[4] J. M. Menter, D. Eatman, M. Bayorh, A. M. Dawaghreh and I. Willis, "Pigment Melanin Scavenges Nitric Oxide in Vitro: Possible Relevance to Keloid Formation," Research Letters in Physical Chemistry, Vol. 2008, 2008, Article ID: 210616.

\section{http://dx.doi.org/10.1155/2008/210616}

[5] M. R. Chedekel, "Photophysics and Photochemistry of Melanin," In: L. Zeise, M. R. Chedekel and T. B. Fitzpatrick, Eds., Melanin: Its Role in Human Photoprotection, Valdenmar, Overland Park, 1994, pp. 11-22.

[6] J. M. Menter and I. Willis, "Electron Transfer and Photoprotective Properties on Melanins in Solution," Pigment Cell Research, Vol. 10, No. 4, 1997, pp. 214-217. http://dx.doi.org/10.1111/j.1600-0749.1997.tb00487.x

[7] J. M. C. Gutteridge, I.-Z. Nagy, L. Maidt and R. A. Floyd, "ADP-Iron as a Fenton Reagent: Radical Reactions Detected by Spin-Trapping, Hydrogen Abstraction, and Aromatic Hydroxylation," Archives of Biochemistry and Biophysics, Vol. 277 No. 2, 1990, pp. 422-428. http://dx.doi.org/10.1016/0003-9861(90)90599-T

[8] B. Roznowki, J. M. Burke, M. E. Boulton, T. Sarna and M. Roznowka, "Human RPE Melanosomes Protect from Photosensitized and Iron-Mediated Oxidation but Become Pro-Oxidant in the Presence of Iron upon Photodegradation," Investigative Ophthalmology and Visual Science, Vol. 49, No. 7, 2008, pp. 2838-2847. http://dx.doi.org/10.1167/iovs.08-1700

[9] L. Louw, "The Keloid Phenomenon: Progress toward a Solution," Clinical Anatomy, Vol. 20, No. 1, 2007, pp. 314. http://dx.doi.org/10.1002/ca.20374

[10] P. D. Butler, M. T. Longaker and G. P. Yang, "Current Progress in Keloid Research and Treatment," Journal of the American College of Surgeons, Vol. 206, No. 4, 2008, pp. 731-741.

http://dx.doi.org/10.1016/j.jamcollsurg.2007.12.001

[11] M. C. Naylor and A. E. Brissett, "Current Concepts in Etiology and Treatment of Keloids," Facial Plastic Surgery, Vol. 28, No. 5, 2012, pp. 504-512.

http://dx.doi.org/10.1055/s-0032-1325644

[12] A. S. Halim, A. Emami, I. Salahshourifar and T. Ponnuraj, "Keloid Scarring: Understanding the Genetic Basis, Advances," Archives of Plastic Surgery, Vol. 39, No. 3, 2012, pp. 184-189. http://dx.doi.org/10.5999/aps.2012.39.3.184

[13] S. B. Russell, J. D. Russell, K. M. Trupin, A. E. Gayden, S. R. Latha Raju and S. M. Williams, "Epigenetically Altered Wound Healing in Keloid Fibroblasts," Journal of Investigative Dermatology, Vol. 130, No. 10, 2012, pp. 2489-2496. http://dx.doi.org/10.1038/jid.2010.162

[14] Y. W. Wirohadidjojo, S. Radiono, A. Budiyanto and H. Soebono, "Cellular Viability, Collagen Deposition and Transforming Growth Factor $\beta 1$ Production among Ultraviolet B-Irradiated Keloids Fibroblasts," Aesthetic Plastic Surgery, Vol. 35, No. 6, 2011, pp. 1050-1055. http://dx.doi.org/10.1007/s00266-011-9732-x

[15] Y.-C. Hsu, M. Hsiao, Y. W. Chien and W.-R. Lee, "Exogenous Nitric Oxide Stimulated Collagen Type I Expression in Keloid Fibroblasts by a cGMP-Dependent Manner," Nitric Oxide, Vol. 16, No. 2, 2006, pp. 258-265.

[16] Y.-C. Hsu, M. Hsaio, L.-F. Wang, Y.-W. Chien and W.-R. Lee, "Nitric Oxide Produced by iNOS Is Associated with Collagen Synthesis and Keloid Scar Formation," Nitric Oxide, Vol. 14, No. 4, 2006, pp. 327-334. http://dx.doi.org/10.1016/j.niox.2006.01.006 
[17] P. R. Crippa, "Oxygen Adsorption and Photoreduction on Fractal Melanin Particles," Colloids and Surfaces B, Vol. 20, No. 4, 2001, pp. 315-319. http://dx.doi.org/10.1016/S0927-7765(00)00206-X

[18] H. Kojima, N. Nakatsubo, K. Kichuchi, S. Kawahara, Y. Kirino, H. Nagoshi, Y. Hirata and T. Nagano, "Detection and Imaging of Nitric Oxide with Novel Fluorescent Indicators: Diaminofluoresceins," Analytical Chemistry, Vol. 70, No. 13, 1998, pp. 2446-2453. http://dx.doi.org/10.1021/ac9801723

[19] J. P. Crow, "Dichlorodihydrofluorescein and Dihydrorhodamine 123 Are Sensitive Indicators of Peroxynitrite in Vitro: Implications for Intracellular Measurement of Reactive Nitrogen and Oxygen Species," Nitric Oxide: Biology and Chemistry, Vol. 1, No. 2, 1997, pp. 145-157. http://dx.doi.org/10.1006/niox.1996.0113

[20] I. Langmuir, "Transactions of the Faraday Society 17: 621 (1921) as cited in W.J. Moore, Physical Chemistry," 3rd Edition, Prentice-Hall, Inc., Englewood Cliffs, 1962, pp. 303-305.

[21] A. R. Kim, Y. Zou, H. S. Kim, J. S. Choi, G. Y. Chang, Y. J. Kim and H. Y. Chung, "Selective Peroxynitrite Scavenging Activity of 3-Methyl-1,2-cyclopentanedione from Coffee Extract," Journal of Pharmacy and Pharmacology, Vol. 54, No. 10, 2002, pp. 1385-1392. http://dx.doi.org/10.1211/002235702760345473

\section{Appendix}

For analysis, of the raw data from the Langmuir plot, the net oxidation of DHR by $\mathrm{NO}_{x}$ was determined by subtracting the contribution of each control curve (see Figure 1). The rate of DHR oxidation is proportional to the formation of $\mathrm{NO}_{x}$; the concentration of steady state concentration of NO is proportional to added SNAP concentration at $t=0$. We found the relationship between rhodamine 123 fluorescence and [NO] by means of a standard curve made by known concentrations of rhodamine $\mathrm{B}^{*}$.

The steady state [NO] was estimated from the halflives of SNAP decomposition $(\tau \sim 5 \mathrm{hr})$ and NO decomposition $(\tau \sim 2 \mathrm{~s})$. These allowed estimation of the respective rate constants for NO arising from decomposition of SNAP, $\left(k_{1}=3.9 \times 10^{-5} \mathrm{~s}^{-1}\right.$ and $k_{2}=0.347 \mathrm{~s}^{-1}$ for decomposition of NO. Treating the process as two consecutive reactions, of the form [20] we get:

$$
[\mathrm{SNAP}] \stackrel{k_{1}}{\longrightarrow} \mathrm{NO} \stackrel{k_{2}}{\longrightarrow} \mathrm{NO}_{\mathrm{x}}
$$

[22] T. Nauser and W. H. Koppenol, "The Rate Constant of the Reaction of Superoxide With Nitrogen Monoxide: Approaching the Diffusion Limit," The Journal of Physical Chemistry A, Vol. 106, No. 16, 2002, pp. 4084-4086. http://dx.doi.org/10.1021/jp025518z

[23] J. S. Beckman and W. H. Koppenol, "Nitric Oxide, Superoxide and Peroxynitrite: The Good, the Bad, and the Ugly," Cell Physiology, Vol. 40, 1996 pp. C1424-C1437.

[24] S. A. Cotton, A. L. Herrick, M. I. V. Jayson and A. J. Freemont, "Endothelial Expression of Nitric Oxide Synthases and Nitrotyrosine in Systemic Sclerosis Skin," The Journal of Pathology, Vol. 189, 1999, pp. 273-278.

[25] A. Dooley, B. Gao, S.-W. Xu, D. J. Abraham, C. M. Black, M. Jacobs and K. R. Bruckdorfer, "Effect of Nitric Oxide and Peroxynitrite on Type I Collagen Synthesis in Normal and Scleroderma Dermal Fibroblasts," Free Radical Biology and Medicine, Vol. 43, No. 2, 2007, pp. 253264.

http://dx.doi.org/10.1016/j.freeradbiomed.2007.04.017

[26] A. Dooley, B. Gao, N. Bradley, D. J. Abraham, C. M. Black, M. Jacobs and K. R. Bruckdorfer, "Abnormal Nitric Oxide Metabolism in Systemic Sclerosis: Increased Levels of Nitrated Proteins and Asymmetric Dimethylarginine," Rheumatology, Vol. 45, No. 6, 2006, pp. 676-684. http://dx.doi.org/10.1093/rheumatology/kei276

In this case, $k_{2} \geq k_{1}$, and NO is consumed as fast as it is formed, leaving a steady-state NO concentration, $[\mathrm{NO}]_{\mathrm{ss}}$. This treatment yields the differential equation for [NO]

$$
\begin{aligned}
\mathrm{d}[\operatorname{SNAP}(t)] / \mathrm{d} t & =-k_{2}[\operatorname{SNAP}(t)] \\
& +k_{1}[\operatorname{SNAP}(o)] \exp \left(-k_{1} t\right)
\end{aligned}
$$

Substituting these values into the integrated equation (see 20) subsequently afforded the value of

$$
[\mathrm{NO}]_{\mathrm{ss}}=1.12 \times 10^{-4}[\operatorname{SNAP}(o)](\mathrm{M})
$$

* Since the absorption/emission maxima of rhodamine $\mathrm{B}$ are red-shifted by $\sim 1100 \mathrm{~cm}^{-1}$ with respect to rhodamine 123 and the quantum yields of fluorescence, $\varphi_{f}$ very similar, we shifted the excitation/emission measurement to $496 \mathrm{~nm}$ and $587 \mathrm{~nm}$. The choice of excitation wavelength was chosen so that the both samples absorbed the same amount of excitation radiation. 